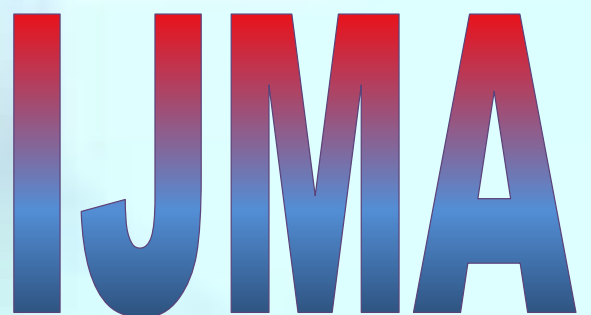

INTERNATIONAL

Journal of MEdical

\section{ARTS}

Volume 3, Issue 1 (Winter 2021)

http://ijma.journals.ekb.eg/

Print ISSN: 2636-4174

Online ISSN: 2682-3780

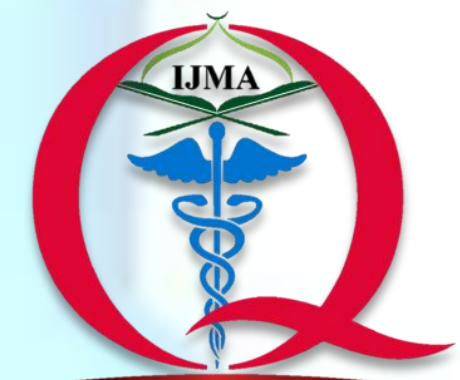

International Jounnal of Medical Arts

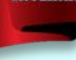




\section{About IJMA}

- International Journal of Medical Arts is the Official Journal of the Damietta Faculty of Medicine, Al-Azhar University, Egypt

- The First Issue was published in July 2019

- It is an International, Open Access, Double-blind, Peerreviewed Journal

- Published four times a year

- Published under the following license: Creative Commons Attribution-ShareAlike 4.0 International Public License (CC BY-SA 4.0). It had updated from the Creative Commons license [CC BY] in volume 2, Issue 4, October 2020

- The Egyptian Knowledge Bank hosts the web site of IJMA

- The Egyptian Knowledge Bank supports IJMA

- IJMA is indexed in the "Directory of Open Access Journals" Indexed on 15 January 2021.

- IJMA follows the regulations of the International Committee of Medical Journal Editors (list date 1/21/20)

- IJMA is a member of The International Society of Managing and Technical Editors

- IJMA is listed in Index Copernicus

- IJMA is listed in Publons, as EKB is an official partner with Clarivate Analytics
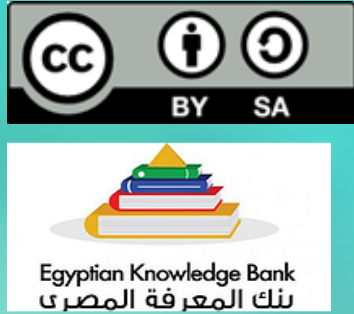

\section{DOAJ}

CMNE

ISMTE

INDEX COPERNICUS

publons 
International Journal of Medical Arts 2021; 3 [1]: 1039-1045.

Available online at Journal Website
https://ijma.journals.ekb.eg/
Main subject [Otorhinolaryngology]

Original article

\title{
Incidence of Dysphagia in Patients with Unilateral Vocal Cord Paralysis
}

\author{
Ibrahim Eldsoky[1]; Wael Fawzy Ismaiel [2] \\ Department of Otorhinolaryngology, Faculty of Medicine, Al-Azhar University, Egypt[1] \\ Department of Otorhinolaryngology, Damietta Faculty of Medicine, Al-Azhar University, Egypt [2]. \\ Corresponding author: Ibrahim Eldsoky \\ Email: ibrahimeldsokyorl@gmail.com
}

Received at: October 09, 2020; Revised at: November 05, 2020; Accepted at: November 08, 2020

DOI: $10.21608 / \mid J M A .2020 .45632 .1190$

\section{ABSTRACT}

Background: It is essential and evaluates dysphagia among patients with UVCP to help the management, improves the quality of life, and prevents secondary complications.

Aim of the work: This research aims to find the incidence of dysphagia in patients with unilateral vocal cord paralysis [UVCP].

Patients and Methods: This study was performed in 245 patients with UVCP; 98 males and 147 females. There were two groups of patients: the non-dysphagia group [130 patients] and the dysphagia group [115 patients]. Assessment of patients was performed by the verified 10-item Eating Assessment Tool [EAT10] and Dysphagia Handicap Index [DHI].

Results: Performing EAT-10 questionnaire revealed average values of $18.5 \pm 9.56$ and $34.3 \pm 11.3$ in the nondysphagia group and dysphagia groups, respectively. $\mathrm{DHI}$ showed mean values of $45.7 \pm 18.12$ and $85.42 \pm 21.7$ in the non-dysphagia group and dysphagia groups, respectively. All of them demonstrated a highly significant variation $[P=0.001]$. Regarding the etiology of UVCP, iatrogenic was the first cause of UVCP; it was the cause of $36.9 \%$ and $36.52 \%$, followed by idiopathic; $23.1 \%$ and $24.34 \%$, intubation injury; $12.6 \%$ and $11.3 \%$, tumor; $10 \%$ and $9.56 \%$, trauma; $8.46 \%$ and $8.69 \%$, thyroid surgery; $4.62 \%$ and $5.22 \%$, and neurodegenerative disease; $4.62 \%$ and $4.35 \%$ of non-dysphagia and dysphagia groups, respectively.

Conclusion: The incidence of dysphagia in unilateral vocal cord paralysis depends mainly on the cause; however, vocal cord paralysis itself increases the incidence of dysphagia whatever the cause.

Keywords: Dysphagia; Unilateral vocal cord paralysis; Laryngeal reflexes; Self-reported swallowing disability; Dysphagia Handicap Index [DHI]

This is an open-access article registered under the Creative Commons, ShareAlike 4.0 International license [CC BY-SA 4.0] [https://creativecommons.org/licenses/by-sa/4.0/legalcode.

Please cite this article: Eldsoky I, Ismaiel WF. Incidence of Dysphagia in Patients with Unilateral Vocal Cord Paralysis. IJMA 2021; 3[1]: 1039-1045. DOI: 10.21608/IJMA.2020.45632.1190

* Main subject and any subcategories have been classified according to the research topic. 


\section{INTRODUCTION}

Vocal fold movement functions by coordinating the contraction of the laryngeal muscles innervated by the vagus nerve and its branches, the recurrent laryngeal nerve, and the superior laryngeal nerve ${ }^{[1]}$.

Unilateral vocal fold immobility [UVFI] may arise secondary to etiologies that are neurogenic or mechanical. Trauma and lesions in the motor cortex, neck, and mediastinum are neurogenic causes. In contrast, the vocal folds' mechanical obstruction may be attributed to intrinsic laryngeal musculature infiltration or disordered cricoarytenoid joint stiffness[2].

UVCP can lead to phonation and swallowing difficulties, irrespective of etiology [3].

Afferent input from the laryngeal region is necessary to enable the various reflexes which protect the respiratory tract from invasion by the foreign body and allow the oral, pharyngeal and esophageal phases to be swallowed [4].

Owing to the high risk of aspiration, impaired swallowing or dysphagia is worrisome, contributing to the possible development of pneumonia. For example, $50 \%$ experience aspiration between patients with dysphagia after a stroke, and almost one-third of all these develop pneumonia and need treatment ${ }^{[5]}$

UVCP arises from damage to one recurrent laryngeal nerve; $70 \%$ to $80 \%$ are caused by two categories: idiopathic [12\%-37\%] and surgical [47\%-56\%] injuries. Surgical causes involve thyroid or parathyroid gland injury, cervical spine, cardiothoracic, neck and head surgery, neurosurgery, and foregut surgery [6].

If the cause of paralysis has been unpredictable, abrupt onset, and correlated with deficiencies of clinical usefulness associated with severe impairment of communication, new-onset dyspnea, dysphagia, aspiration [7,8]

Symptoms of dysphonia, aphonia, and dyspnea, reduced cough strength, and dysphagia can result from the resulting glottal deficiency. The influence of UVFI on voice, breathing, and quality of life-related to voice has been thoroughly studied[8].
Therefore, it is important to better diagnose and assess dysphagia between UVCP patients to improve quality of life and prevent secondary complications [3].

\section{AIM OF THE WORK}

This research aims to find dysphagia's incidence in patients with unilateral vocal cord paralysis [UVCP].

\section{PATIENTS AND METHODS}

This retrospective research was conducted on 245 patients with UVCP, 147 females and 98 males. The study was conducted in the Otorhinolaryngology departments of Al-Azhar University Hospital, Damietta, and Al-Hussein University Hospital, Cairo, between July 2017 and July 2020.

The patients gave written informed consent for their clinical records to be included in this research. The Institutional Review Board [IRB] approval was obtained from Al-Azhar University Hospital for this study.

Participants over 18 years of age have been involved in the research while the exclusion criteria were that who had dysphagia due to other causes than vocal cord lesions such as drugs, esophageal or gastric cancer, esophageal spasm, achalasia, heartburn, or history of stomach, esophageal and head and neck surgery. Also, concomitant vocal fold lesions, superior laryngeal nerve impairment without proof of impaired movement of the vocal fold [VF], bilateral impairment of VF mobility, normal or abnormal bilateral VF mobility are excluded.

All demographic data of the patients were recorded, such as age, sex, residence, education, the period of the disease, lesion laterality, and onset of dysphagia.

\section{Testing instrumentation for dysphagia:}

All patients with UVCP were confirmed by video-laryngoscopy.

Self-reported swallowing disabilities were the primary result measure. This was evaluated pre and post-surgery with the validated 10-item Eating Assessment Tools [EAT-10], with scores 3 deemed abnormal, as indicated by normative results[9].

Dysphagia Handicap Index [DHI] has been 
adopted[10]. The total score was registered for each instrument. The existence of dysphagia was defined by $\mathrm{DHI}$ total scores higher than 5 and EAT-10 total scores higher than 216.

Statistical analysis: Data analysis was conducted utilizing SPSS, version 23. The data is represented as average values [with standard deviations [SDs]] and is 2-tailed in all statistical tests. For the data, non-parametric tests have been applied. To identify variations among groups, chi-square tests [X2], paired t-test, and student $t$ test has been utilized [according to ANOVA test of variance]. The $p<0.05$ values have been deemed statistically significant.

\section{RESULTS}

The research involved 245 patients with UVCP, 98 males and 147 females. Of them, 115 patients suffered from dysphagia; there had been 40 men and 75 women. Their ages ranged between 18 and 89 years, with a mean \pm SD of $59.8 \pm 5.69$ years in the non-dysphagia group and $62.3 \pm 6.97$ years in the dysphagia group. As regard the education level; 33 [25.4\%] and 9 [7.8\%] were ignorant, 23 [17.7\%] and 13 [11.3] were primary school, 34 [26.1\%] and 41 [35.7\%] high school, and 40 [30.8\%] and 52 [45.2\%] had university degree in non-dysphagia and dysphagia groups, respectively. As regard laterality, 112 were right-sided; 61 [46.9\%] of the non-dysphagia group and 51 [44.3\%] of the dysphagia group, while the left-sided lesion was found in 133 patients 69
[53.1\%] if the non-dysphagia group and 64 [55.7\%] of the dysphagia group. Our patients' residence was 121 rural and 124 urban. They had a mean disease duration of $2.62 \pm 1.86$ years and $1.8 \pm$ 1.05 years in non-dysphagia and dysphagia groups, respectively [Table 1].

The most common symptoms were presented in non-dysphagia group and dysphagia group as dysphagia [ $0 \%$ and $100 \%$ ], dysphonia [ $19.2 \%$ and $62.6 \%$ ], dyspnea [29.2\% and 27.8\%], cough [16.9 $\%$ and $13.9 \%]$, frequent sputum $[9.23 \%$ and $6.09 \%$ ] and globus sensation [3.85\% and $1.74 \%$ ], respectively [Table 2].

Performing EAT-10 questionnaire showed mean values of $18.5 \pm 9.56$ and $34.3 \pm 11.3$ in the non-dysphagia group and dysphagia groups, respectively. Dysphagia Handicap Index showed mean values of $45.7 \pm 18.12$ and $85.42 \pm 21.7$ in the non-dysphagia group and dysphagia groups, respectively. As seen in the table, they all showed a highly significant variation $[P=0001]$ [3]. On studying the etiology of UVCP, iatrogenic was the first cause of UVCP, it was the cause of $36.9 \%$ and $36.52 \%$, followed by idiopathic; $23.1 \%$ and $24.34 \%$, intubation injury; $12.6 \%$ and $11.3 \%$, tumor; $10 \%$ and $9.56 \%$, trauma; $8.46 \%$ and $8.69 \%$, thyroid surgery; $4.62 \%$ and $5.22 \%$, and neurodegenerative disease; $4.62 \%$ and $4.35 \%$ of non-dysphagia and dysphagia groups, respectively [table 4].

Table [1]: Demographic data of the studied patients

\begin{tabular}{|c|c|c|c|c|c|c|c|}
\hline \multicolumn{2}{|l|}{ UVCP } & \multicolumn{2}{|c|}{ Without dysphagia } & \multicolumn{2}{|c|}{ With dysphagia } & \multicolumn{2}{|c|}{ Significance } \\
\hline & & No. & $\%$ & No. & $\%$ & Test & $P$ \\
\hline \multirow[t]{2}{*}{ Gender } & Males & 58 & 44.6 & 40 & 50.0 & 0.294 & 0.107 \\
\hline & Females & 72 & 55.4 & 75 & 50.0 & 0.019 & 0.335 \\
\hline \multicolumn{2}{|l|}{ Age [years] } & \multicolumn{2}{|c|}{$59.8 \pm 5.69 ; 19-86$} & \multicolumn{2}{|c|}{$63.2 \pm 6.97 ; 19-89$} & 0.011 & 0.491 \\
\hline \multirow[t]{4}{*}{ Education } & Illiterate & 33 & 25.4 & 9 & 7.8 & 13.96 & $0.000^{*}$ \\
\hline & Primary school & 23 & 17.7 & 13 & 11.3 & 5.418 & $0.007^{*}$ \\
\hline & High school & 34 & 26.1 & 41 & 35.7 & 6.112 & $0.005^{*}$ \\
\hline & University & 40 & 30.8 & 52 & 45.2 & 3.455 & $0.009^{*}$ \\
\hline \multirow[t]{2}{*}{ Laterality } & Right & 61 & 46.9 & 51 & 44.3 & 0.852 & 0.096 \\
\hline & Left & 69 & 53.1 & 64 & 55.7 & 0.812 & 0.099 \\
\hline \multirow[t]{2}{*}{ Residence } & Rural & 76 & 58.5 & 45 & 39.1 & 1.951 & $0.041^{*}$ \\
\hline & Urban & 54 & 41.5 & 70 & 60.9 & 2.347 & $0.017^{*}$ \\
\hline \multicolumn{2}{|c|}{ Disease duration [Years] } & \multicolumn{2}{|c|}{$\frac{1}{2.62 \pm 1.86}$} & \multicolumn{2}{|c|}{$1.80 \pm 1.05$} & 2.13 & 0.0324 \\
\hline
\end{tabular}

UVCP: unilateral vocal cord paralysis; $P<0.05=$ significant. 
Table [2]: Common symptoms of the studied patients.

\begin{tabular}{|l|c|c|c|c|c|c|}
\hline \multirow{2}{*}{ Symptoms of UVCP } & \multicolumn{2}{|c|}{ Without dysphagia } & \multicolumn{2}{c|}{ With dysphagia } & \multicolumn{2}{c|}{ Significance } \\
\cline { 2 - 7 } & $\mathrm{N}=130$ & $\%$ & $\mathrm{~N}=115$ & $\%$ & $\mathrm{X}^{2}$ & $\mathrm{P}$ \\
\hline Dysphagia & 0 & 0.0 & 115 & 100 & 75.82 & $0.000^{*}$ \\
\hline Dysphonia & 25 & 19.2 & 72 & 62.6 & 11.871 & $0.000^{*}$ \\
\hline Dyspnea & 38 & 29.2 & 32 & 27.8 & 0.091 & 0.144 \\
\hline Cough & 22 & 16.9 & 16 & 13.9 & 0.127 & 0.085 \\
\hline Sputum/salivation & 12 & 9.23 & 7 & 6.09 & 0.139 & 0.074 \\
\hline Globus sensation & 5 & 3.85 & 2 & 1.74 & 1.064 & 0.058 \\
\hline
\end{tabular}

$X^{2}=$ Chi square test, ${ }^{*} \mathrm{P}<0.05=$ significant.

Table [3]: Outcome of the questionnaire.

\begin{tabular}{|l|c|c|c|c|}
\hline EAT-10 & Without dysphagia & With dysphagia & t-test & P \\
\hline Range & $0-40$ & $0-40$ & & \\
\hline Mean \pm SD & $18.5 \pm 9.56$ & $34.3 \pm 11.3$ & 9.151 & $0.001^{*}$ \\
\hline DHI & & & & \\
\hline Range & $5-100$ & $7-100$ & & \\
\hline Mean \pm SD & $45.7 \pm 18.12$ & $85.42 \pm 21.7$ & 9.064 & $0.001^{*}$ \\
\hline
\end{tabular}

${ }^{*} \mathrm{P}<0.05=$ significant.

Table [4]: Etiology of UVCP of the studied patients.

\begin{tabular}{|l|c|c|c|c|c|c|}
\hline \multirow{2}{*}{ Etiology of UVCP } & \multicolumn{2}{|c|}{ Without dysphagia } & \multicolumn{2}{c|}{ With dysphagia } & \multicolumn{2}{c|}{ Significance } \\
\cline { 2 - 7 } & $\mathrm{N}=130$ & $\%$ & $\mathrm{~N}=115$ & $\%$ & $\mathrm{X}^{2}$ & $\mathrm{P}$ \\
\hline Idiopathic & 30 & 23.1 & 28 & 24.34 & 0.823 & 0.081 \\
\hline latrogenic & 48 & 36.9 & 42 & 36.52 & 0.076 & 0.247 \\
\hline Intubation & 16 & 12.6 & 13 & 11.3 & 0.234 & 0.172 \\
\hline Tumor and radiation & 13 & 10.0 & 11 & 9.56 & 0.211 & 0.145 \\
\hline Accident and trauma & 11 & 8.46 & 10 & 8.69 & 0.735 & 0.092 \\
\hline Thyroid surgery & 6 & 4.62 & 6 & 5.22 & 0.205 & 0.149 \\
\hline Neural degeneration & 6 & 4.62 & 5 & 4.35 & 0.086 & 0.198 \\
\hline
\end{tabular}

$X^{2}=$ Chi square test, $P>0.05=$ non-significant.

\section{DISCUSSION}

To the best of our understanding, that is the first research to compare dysphagia with nondysphagia in UVCP patients to find the incidence of dysphagia in UVCP patients in our country, Egypt. It was mentioned by many previous studies as well as our observation that UVCP can cause dysphagia in many patients. So, we try to find the incidence of dysphagia in those patients to give a spot of light on this phenomenon and try to find a solution in the next literature.

Although it is relatively easy to diagnose UVCP with a laryngoscope, insufficient knowledge of the disease burden on the population of patients captures both physical and etiological symptoms. This is notable because clinicians need more information about the incidence of dysphagia in UVCP. There are now attempts to better assess the degree of UVCP dysphagia. However, further research is needed on specific instrumentations of UVFP and the interplay with the consequent somatic manifestations [e.g., voice, swallowing, breathing] [3].

This study was performed on 245 UVCP patients; of them, 115 suffered from dysphagia, and the rest [130 patients] had no dysphagia. It was found that females were more prominent than males of both groups, but they showed a nonsignificant difference between males and females in both groups.

Via the application to a single patient cluster with different definitions, Schiedermayer et al..[11] found the impact of dysphagia prevalence estimated in those with UVCP.

Also, in Cates et al..[8] the study, more than two-thirds of UVFI patients recorded symptoms of dysphagia. Other research agreed on these results and estimated that among $50 \%$ and $61 \%$ of those with UVFI may have some degree of swallowing dysfunction [12-13].

Comparison of age in both groups had a mean of 59.8 and 63.2 years in non-dysphagia group 
and dysphagia group, respectively, with insignificant value $[p=0.491]$. The level of education was studied; ignorance was found in $25.4 \%$, and $7.8 \%$ of patients, $17.7 \%$ and 11.3 had a primary school, $26.1 \%$ and $35.7 \%$ of patients, and university graduated was found in $30.8 \%$ and $45.2 \%$ of patients with non-dysphagia and dysphagia group, respectively. They all showed a statistically significant difference.

The level of education was studied by Francis et al.[14] and found some high school [6\%], high school [19\%], some college [25\%], college [36\%], university [4\%], which was comparable to our study.

As regard laterality, 112 were right-sided; 61 [46.9\%] of the non-dysphagia group and 51 [44.3\%] of the dysphagia group, while the leftsided lesion was found in 133 patients 69 [53.1\%] if the non-dysphagia group and 64 [55.7\%] of the dysphagia group. Our patients' residence was 121 rural and 124 urban. They had a mean disease duration of $2.62 \pm 1.86$ years and $1.8 \pm 1.05$ years in non-dysphagia and dysphagia groups, respectively.

These data were coinciding with Cates et al.[8] found that the median period of UVFI from the start of symptoms to the date of the surgery was 36 months, with the shortest reported duration being 7 months.

The delay in diagnosis and treatment can worsen the psychosocial effects of UVCP[8,14]. Postponed determination and treatment are normal, and patients can encounter signs and symptoms for years before introducing, which can dramatically affect their point of view [6,15].

The symptoms of dysphagia were identified as the clinic appointment's chief complaint. The symptoms were studied in non-dysphagia group and dysphagia group as dysphagia $[0 \%$ and $100 \%$ ], dysphonia [ $19.2 \%$ and $62.6 \%$ ], dyspnea [29.2\% and $27.8 \%$ ], cough [16.9 \% and $13.9 \%$ ], frequent sputum and salivation [9.23\% and $6.09 \%$ ] and globus sensation $[3.85 \%$ and $1.74 \%]$, respectively.

Francis et al. [14] illustrated the symptoms of UVCP. They found that $97 \%$ had dysphonia, $72 \%$ had dysphagia, $22 \%$ had salivation, $50 \%$ ear liquids only, $14 \%$ eat pureed, $42 \%$ eat solid, $58 \%$ dyspnea, $86 \%$ cough, $78 \%$ require surgery, and $68 \%$ require injection, while $30 \%$ of cases did not require treatment.

Abnormal swallow was considered when total EAT-10 total score $>2$ or DHI score $>5$. EAT-10 questionnaire in the present study showed mean values of $18.5 \pm 9.56$ and $34.3 \pm 11.3$ in nondysphagia and dysphagia groups, respectively. $\mathrm{DHI}$ showed mean values of $45.7 \pm 18.12$ and $85.42 \pm 21.7$ in the non-dysphagia group and dysphagia groups, respectively. All of them demonstrated a highly significant variation $[P=$ 0.001]. So, the majority of patients undergoing instrumental evaluation have been shown to have abnormal swallowing function, which confirmed by Schiedermayer et al.[11], who stated the same findings and recommended completion based on the results of the clinical assessment. The range of incidence estimates in this research was comparable to other research utilizing a similar mean of dysphagia examining the incidence of dysphagia in UVCP [2,14].

Cates et al.[8] reported that $20 \%$ of patients with abnormal preoperative EAT-10 had a postoperative score inside the normal range. Although most patients with abnormal baseline scores kept going to report symptoms after surgery, the mean EAT-10 score improved by approximately 5 points. They added that their research results showed that dysphagia is prevalent in people with UVFI and that treatment improves, but does not fully remove, the symptoms of dysphagia. This may be due to pharyngeal weakness in UVF[[16].

Regarding the etiology of UVCP, iatrogenic was the first cause of UVCP; it was the cause of $36.9 \%$ and $36.52 \%$, followed by idiopathic; $23.1 \%$ and $24.34 \%$, intubation injury; $12.6 \%$ and $11.3 \%$, tumor; $10 \%$ and $9.56 \%$, trauma; $8.46 \%$ and $8.69 \%$, thyroid surgery; $4.62 \%$ and $5.22 \%$, and neurodegenerative disease; $4.62 \%$ and $4.35 \%$ of non-dysphagia and dysphagia groups, respectively.

Our causes agree with Cates et al.[8] as they found that UVFI etiology was iatrogenic in [55\%], idiopathic in [29\%], neoplastic [9\%], traumatic $[5 \%]$, or radiation-related [2\%]. 
Also, this agreed with Schiedermayer et al.[11] who studied 415 UVCP cases and found the cause was 206 iatrogenic, 107 idiopathic, 31 tumors, 20 intubation, 19 accidental trauma, and four degenerative diseases. They added that more instrumental evaluation was most commonly correlated with etiological categories; 33 [31\%] of idiopathic UVCP patients complained of dysphagia.

However, Dworkin and Treadway[17] opposed these results and found that no form of dysphagia was reported in $70 \%$ of adult retrospective cohorts diagnosed with idiopathic UVP.

While it can be predicted that idiopathic and iatrogenic etiologies for UVCP would similarly affect swallowing function, this research found insignificant differences among non-dysphagia and dysphagia patients. But Dworkin and Treadway[17] stated that "patients with an iatrogenic etiology more frequently complained of dysphagia, had higher DHI or EAT-10 scores", showed increased reference for instrumental dysphagia evaluation, and showed higher aspiration rates than those with idiopathic etiology. However, through quantitative analysis of videofluoroscopic assessment, further comparison of these two patient populations is required to better identify similarities and differences in swallowing physiology.

The study had some limitations; the first is the retrospective nature of the study that had a lack of information about preoperative dysphagia of some causes such as tumors, thyroid, and other head and neck surgeries. Patients with post-operative edema and the potential for transient aggravation of swallowing after surgical intervention in a shortterm follow-up can account for ignorance of the actual cause of dysphagia.

Conclusion: The incidence of dysphagia in UVCP depends mainly on the cause. However, vocal cord paralysis itself increases the rate of dysphagia, whatever the etiology.

Financial and Non-Financial Relationships and Activities of Interest

None

\section{REFERENCES}

1. Paquette CM, Manos DC, Psooy BJ. Unilateral vocal cord paralysis: a review of CT findings, mediastinal causes, and the course of the recurrent laryngeal nerves. Radiographics. 2012; 32:721-740. DOI: 10.1148/RG.323115129.

2. Prasad VMN, Fakhoury R, Helou D, Lawson G, Remacle M. Unilateral vocal fold immobility: a tertiary hospital's experience over 5 years. Eur Arch Otorhinolaryngol. 2017; 274:2855-2859. DOI: 10.1007/ s00405-017-4528-5.

3. Zhou D, Jafri M, Husain I. Identifying the Prevalence of Dysphagia among Patients Diagnosed with Unilateral Vocal Fold Immobility. Otolaryngol Head Neck Surg. 2019;160 [6]:955-964. DOI: 10.1177/ 0194599818815885.

4. Kaneoka A, Pisegna JM, Inokuchi H, Goto T, Nito T, Stepp CE, LaValley MP, Haga N, Langmore SE. Relationship between laryngeal sensory deficits, aspiration, and pneumonia in patients with dysphagia. Dysphagia. 2018; 33:192-199. DOI: 10. 1007/s00455- 017-9845-8

5. Hinchey JA, Shephard T, Furie K, Smith D, Wang D, Tonn S; Stroke Practice Improvement Network Investigators. Formal dysphagia screening protocols preventing pneumonia. Stroke. 2005; 36: 1972-1976. DOI: 10.1161/01.STR.0000177 529.86868.8d.

6. Francis DO, Williamson K, Hovis K, Gelbard A, Merati AL, Penson DF, Netterville JL, Garrett CG. Effect of injection augmentation on need for framework surgery in unilateral vocal fold paralysis. Laryngoscope. 2016; 126 [1]: 128-134. DOI: 10.1002/lary.25431.

7. Asik MB, Karasimav O, Birkent $H$, Merati AL, Gerek M, Yildiz Y. Airway and respiration parameters improve following vocal fold medialization: a prospective study. Ann Otol 
Rhinol Laryngol. 2015;124[12]: 972-977. DOI: $10.1177 / 0003489415593558$

8. Cates DJ, Venkatesan NN, Strong B, Kuhn MA, Belafsky PC. Effect of Vocal Fold Medialization on Dysphagia in Patients with Unilateral Vocal Fold Immobility. Otolaryngol Head Neck Surg. 2016; 155 [3]: 454-7. DOI: 10.1177/0194599816645765.

9. Belafsky PC, Mouadeb DA, Rees CJ, Pryor JC, Postma GN, Allen J, Leonard RJ. Validity and reliability of the Eating Assessment Tool [EAT-10]. Ann Otol Rhinol Laryngol. 2008; 117:919-924. DOI: 10.1177/ 000348940811701210.

10.Silbergleit AK, Schultz L, Jacobson BH, Beardsley T, Johnson AF. The Dysphagia handicap index: development and validation. Dysphagia 2012; 27 : 46-52. DOI: 10.1007/ s00455-011-9336-2

11.Schiedermayer B, Kendall KA, Stevens M, Ou Z, Presson AP, Barkmeier-Kraemer JM. Prevalence, incidence, and characteristics of dysphagia in those with unilateral vocal fold paralysis. Laryngoscope 2020; 130 [10]:2397-2404. DOI: 10.1002/ lary. 28401.

12. Hendricker RM, deSilva BW, Forrest LA. Gore-Tex medialization laryngoplasty for treatment of dysphagia. Otolaryngol. Head Neck Surg. 2010; 142:536-539. DOI: 10. 1016/ j.otohns.2009.12.004.
13.Brunner E, Friedrich G, Kiesler K, Chibidziura-Priesching J, Gugatschka M. Subjective breathing impairment in unilateral vocal fold paralysis. Folia Phoniatr Logop. 2011; 63: 142 - 146. DOI: 10.1159/ 000316320.

14.Francis DO, Sherman AE, Hovis KL, Bonnet K, Schlundt D, Garrett CG, Davies L. Life experience of patients with unilateral vocal fold paralysis. JAMA Otolaryngol Head Neck Surg. 2018 May 1;144[5]:433-439. DOI: 10.1001/jamaoto.2018.0067.

15.Spataro EA, Grindler DJ, Paniello RC. Etiology and time to presentation of unilateral vocal fold paralysis. Otolaryngol Head Neck Surg. 2014; 151[2]: 286 - 293. DOI: 10.1177/0194599814531733.

16.Domer AS, Leonard R, Belafsky PC. Pharyngeal weakness and upper esophageal sphincter opening in patients with unilateral vocal fold immobility. Laryngoscope. 2014; 124:2371-2374. DOI: 10.1002/lary.24779.

17.Dworkin JP, Treadway C. Idiopathic vocal fold paralysis: clinical course and outcomes. J Neurol Sci 2009; 284: 56 - 62. DOI: 10.1016/ j.jns.2009.04.004. 


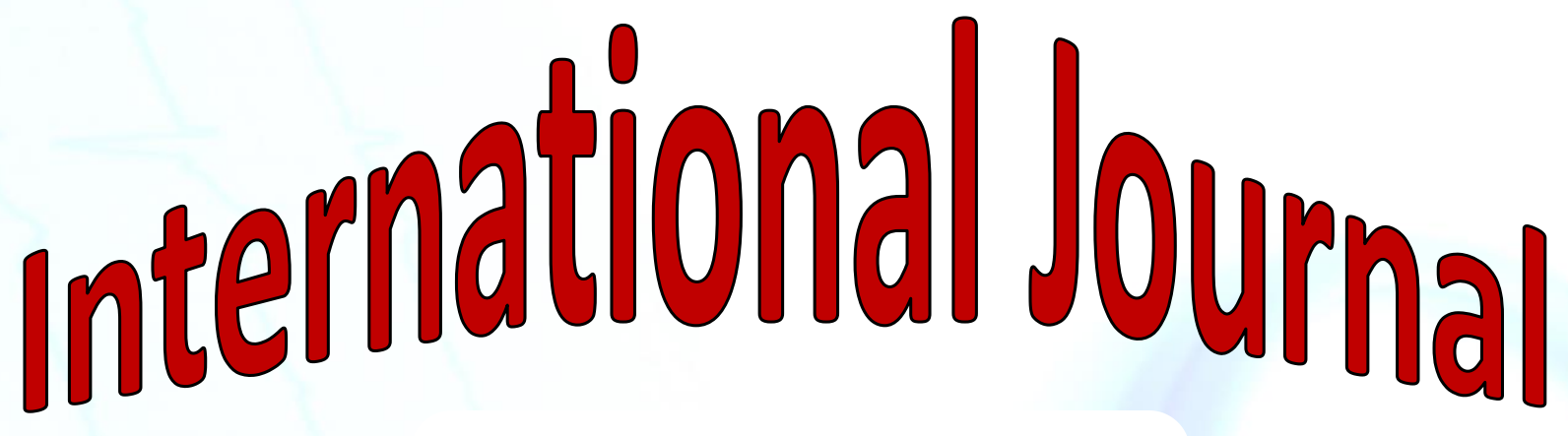

https://ijma.journals.ekb.eg/

Print ISSN: 2636-4174

Online ISSN: 2682-3780

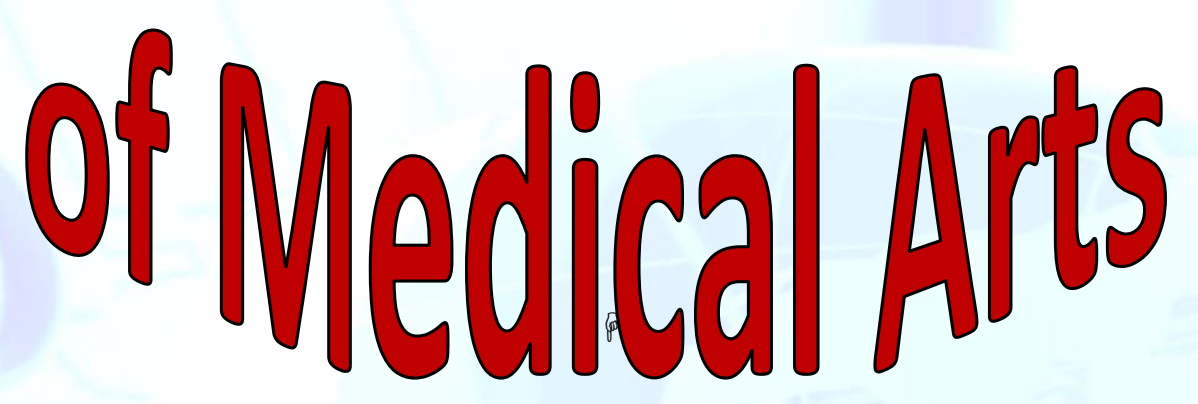

